\title{
Dismantling clichés about immigration and health
}

\author{
G. Burillo-Putze' ${ }^{1}$ X. Balanzó ${ }^{2}$
}

Los primeros trabajos sobre inmigración y atención sanitaria en España comienzan a publicarse entre mediados de los años $80^{1} \mathrm{y}$ principios de los $90^{2}$, aunque la eclosión de estudios parece producirse en torno al año $2000^{3-5}$. Sin pretender ser exhaustivos, la mayoría de ellos se han dedicado al estudio de enfermedades infecciosas ${ }^{6,7}$, atención a la mujer durante el embarazo ${ }^{8}$ y población pediátrica ${ }^{9}$. Otro grupo de trabajos se ha focalizado en sus condiciones sociolaborales ${ }^{10}$, la repercusión de su asistencia en el sistema de salud, los aspectos psiquiátricos ligados a su proceso migratorio ${ }^{11,12}$ así como en su asistencia inicial $^{13-17}$. Aunque hay una cantidad de trabajos apreciable en el ámbito de la atención primaria ${ }^{18-20}$, pocos estudios han abordado los aspectos relacionados con la opinión, problemática y demandas de sus profesionales ${ }^{21}$.

Según los datos del Ministerio de Trabajo e Inmigración, a finales de 2009 había en España 4.791.232 inmigrantes con permiso de residencia, lo que supone en torno al $10 \%$ de la población española. Da cuenta de su crecimiento exponencial el que 11 años antes esta cifra era de 720.000 ciudadanos. En determinadas poblaciones representan un $20 \%$ de sus habitantes, porcentaje similar a otros países europeos, y en barrios de grandes ciudades pueden representar hasta el 40-50\%. La edad media supera ligeramente los 33 años. Entre 1999 y 2009 la población española ha crecido en seis millones de personas, mientras que la población extranjera con autorización de residencia lo ha hecho en cerca de cuatro millones. Ello supone que el $62,30 \%$ del crecimiento de la población de España se debe a la inmigración.

Por continentes, el colectivo europeo contabiliza 1.872 .505 ciudadanos (formado en mayor proporción por población rumana -751.688- y británica -222.039-), Iberoamérica 1.588.442 ciudadanos (con mayor

1. Servicio de Urgencias. Hospital Universitario de Canarias. Tenerife.

2. Servicio de Cuidados Intensivos. Hospital de Mataró. Barcelona.
Correspondencia:

Guillermo Burillo-Putze

Hospital Universitario de Canarias

Servicio de Urgencias

Crta. La Cuesta-Taco, s/n

La Laguna

38320 Tenerife

E-mail: gburillo@huc.canarias.org 
proporción de colectivos de Ecuador -440.000- y Colombia -287.010-), África con 994.000 ciudadanos (procedentes de Marruecos, 767.784) y Asia con 299.743 (ciudadanos chinos 151.547). A los datos anteriores habría que añadir la inmigración irregular, la cual podría oscilar según datos de diferentes colectivos y ONG entre 600.000 y 800.000 personas e incluso algunos autores dan cifras de 1.500 .000 ciudadanos $^{22}$.

El trabajo de Fuertes y col $^{23}$ publicado en este número contribuye a desmontar tópicos sobre la inmigración y la sanidad, a la vez que permite mejorar el conocimiento del fenómeno migratorio mediante datos, además de comparar éstos con la opinión de los profesionales sanitarios. La combinación de métodos de investigación cuantitativa y cualitativa ofrece unos interesantes resultados.

Así, aunque según los profesionales los inmigrantes usan más los servicios sanitarios que la población autóctona, vemos cómo la realidad es otra, con un $10 \%$ menos de utilización de la atención primaria $^{23}$. Además, cuando ingresan en un hospital, sus costes son también menores ${ }^{24}$. Cabría pensar que esto se debe a una mayor utilización de los servicios de urgencias, aunque una vez más las cifras demuestran lo contrario: en general usan las urgencias hospitalarias en la misma proporción que la población autóctona, por los mismos tipos de patologías (en general banal), aunque más en horario nocturno ${ }^{25}$ y por pacientes más jóvenes ${ }^{26,27}$. Estos hechos son congruentes con su pirámide poblacional y, como afirman algunos de los entrevistados por Fuertes y col, coincidiendo con las finalización de su jornada laboral ${ }^{23}$.

Otro tópico a desmontar es el de las enfermedades transmisibles. Como afirma Gabriela Picco, la experiencia demuestra que los inmigrantes no suelen ser vectores de éstas (con probable excepción de la tuberculosis) pero sí están expuestos en los países receptores a condiciones de vulnerabilidad que los predisponen a adquirirlas: infección por el virus de la inmunodeficiencia humana (VIH), por el virus de la hepatitis B y tuberculosis, entre otras ${ }^{28}$. También el trabajo de Roca y $\mathrm{col}^{3}$ sugiere que las enfermedades importadas predominantes son sobre todo las de distribución cosmopolita y asociadas a situaciones de precariedad económica, es decir que perpetuar las condiciones de pobreza y marginalidad en el país receptor puede constituir un medio propicio para el desarrollo y transmisión de enfermedades importadas. Dado que la incidencia de tuberculosis parece haber ido aumentando con los años a expensas de los inmigrantes, tanto en Navarra ${ }^{29}$ como en otras regiones españolas ${ }^{30}$, sus diferencias clínico-epidemiológicas con la población autóctona (sujetos jóvenes, sin otros factores de comorbilidad, falta de seguimiento clínico) sí que parecen necesarios programas de salud específicos para su diagnóstico y tratamiento precoz ${ }^{31}$.

El estudio de Fuertes y col se ha realizado en las zonas con alta presencia de inmigrantes, y fundamentalmente procedentes de Ecuador, por lo que por un lado sus resultados no son extrapolables al conjunto de la asistencia sanitaria navarra, pues a nivel foral probablemente el impacto de la inmigración sea menor que el aquí analizado ${ }^{23}$. Obviamente, a mayor presión demográfica de la inmigración mejor conocimiento y valor de las percepciones de los profesionales, aunque en este caso el idioma juegue a favor de estas percepciones. Ya en otro reciente estudio basado en los sanitarios se observaba cómo la barrera 
idiomática, la necesidad de dedicarles más tiempo y la exigencia de materiales y programas específicos se veían como factores claves para su mejor asistencia, no siendo la primera preocupación la competencia profesional en enfermedades tropicales emergentes sino la competencia cultural ${ }^{21}$, área en la que el grupo de Fuertes es pionero ${ }^{17}$. Parte de esta competencia cultural se observa en las respuestas de los profesionales navarros de Atención Primaria, pues inicialmente parece que los tópicos influyen en su percepción, aunque luego en las entrevistas focales se observa una comprensión del fenómeno migratorio y un mayor conocimiento de sus condicionantes socioculturales y laborales ${ }^{23}$.

Preocupa en cualquier caso las actividades preventivas: dejando de lado las enfermedades infecciosas, aspectos como la salud cardiovascular $^{7,32}$, las condiciones de trabajo ${ }^{33}$ y la atención a niños ${ }^{9}$ y mujeres ${ }^{8}$ se perfilan como áreas de mejora, pues la población ahora joven y sana tiene como prioridad la búsqueda de recursos económicos. Los jóvenes de hoy serán los adultos de mañana y, aunque parece que fenómenos como el consumo de alcohol, la drogadicción o la infección por VIH son mucho menores que en los colectivos autóctonos, debemos anticiparnos en su futura morbilidad ligada a la sociedad del bienestar (de la abundancia) en que se hallan inmersos.

En nuestra opinión, inmigración no es en absoluto igual a problemas sanitarios, sino a retos médicos y sociales, a enriquecimiento cultural en una sociedad moderna plural y global. Mejorar el conocimiento clínico mediante estudios como el presente ${ }^{23}$ y ahondar en la competencia cultura ${ }^{17}$ evitará miedos y permitirá una asistencia sanitaria de calidad en una parte cada día más importante de nuestra sociedad.

\section{BIBLIOGRAFÍA}

1. BaLAnZó X, BADA JL, GonzÁlez CA. La atención sanitaria en la población africana residente en la comarca del Maresme. Rev San Hig Pub 1984; 58: 769-778.

2. BaLAnZó X. Enfermedades importadas y medicina de la inmigración. Aten Prim 1991; 8: 527-529.

3. Roca C, Balanzó X, Fernández Roure JL, Sauca G, Savall R, Gascón J et al. Enfermedades importadas en inmigrantes africanos: estudio de 1.321 pacientes. Med Clin (Barc) 2002; 119: 616-619.

4. HUERGa H, LóPEZ-VÉLEz R. Imported malaria in immigrant and travelling children in Madrid, Eur J Clin Microbiol Infect Dis 2001; 20: 591-593.

5. HerRero M GonZález E, ValvERDE 7. Caballero D. Utilización del cuestionario Prime-MD para la detección de desórdenes mentales en mujeres inmigrantes iberoamaricanas e hispanohablantes. Med Clin (Barc) 2001; 117: 716-717.

6. Roca C, Balanzó X, Sauca G, Fernández Roure JL, Boixeda R, Ballester M. Uncinariasis importada por inmigrantes africanos: estudio de 285 casos. Med Clin (Barc) 2003; 121: 139-141.

7. Gascón J, Albajar P, Cañas E, Flores M, Gómez i Prat J, Herrera RN et al. Diagnóstico y tratamiento de la cardiopatía chagásica crónica en áreas donde la infección por Trypanosomoa cruzi no es endémica. Rev Esp Cardiol 2007; 60: 285-293.

8. De la Torre J, Coll C, Coloma M, Martín Ji, Padrón E, González González NL. Control de gestación en inmigrantes. An Sist Sanit Navar 2006; 29 (Supl. 1): 49-61. 
9. Poch J, Montesdeoca A, Hernández Borges A, Aparicio Jl, Herranz M, López Almaraz R et al. Valoración del niño inmigrante. An Sist Sanit Navar 2006; 29 (Supl. 1): 35-47.

10. Parra A, Fernández Baraibar J, García López V, Ayestarán JR, Extramiana E. Mercado de trabajo, salud laboral e inmigración. An Sist Sanit Navar 2006; 29 (Supl. 1): 77-95.

11. Ochoa E, Vicente N, Lozano M. Síndromes depresivos en la población inmigrante. Rev Clin Esp 2005; 205: 116-118.

12. Martínez Moneo M, Martínez Larrea A. Patología psiquiátrica en el inmigrante. An Sist Sanit Navar 2006; 29 (Supl. 1): 63-75.

13. Supervía A, Del Baño F, Esteve E, Aguirre A, Campodarve I, Pallàs O. Tuberculosis en población inmigrante: casos diagnosticados en urgencias según el lugar de procedencia. Emergencias 2009; 21: 410-414.

14. Rodríguez del Rosario C, Núñez Díaz S, García de Carlos P, Rodríguez Palmero I, Mahtani Mahtani V, Hernández Rodríguez MA et al. Características de la asistencia sanitaria a la llegada de inmigrantes africanos en las Islas Canarias. Un estudio descriptivo. Emergencias 2008; 20: 411-418.

15. Matos Castro S, Padrón Peña MP. Necesidades de asistencia a los inmigrantes ilegales recién llegados en cayuco a Tenerife. Emergencias 2008; 20: 405-410.

16. Hernández Sánchez MJ, Segura Clavell J, Burillo-Putze G. Papel clave de los servicios de emergencias en la tragedia de la inmigración ilegal por vía marítima. Emergencias 2008; 20: 377-379.

17. Fuertes C, Trujillo E, Pinillos M, Balanzó X, Miró O, Burillo-Putzé G. La atención a la diversidad en urgencias. An Sist Sanit Navar 2010; 33 (Supl. 1): 149-161.

18. Arce A, Í̃̃Igo J, Cabello L, BurgoA M. Tubeculosis e inmigración en un área sanitaria de Madrid. Situación epidemiológica y evolución de la década 19942003. Med Clin (Barc) 2005; 125: 210-212.

19. Ros Cervera G, álvarez Fernández M, Moreno Galarza G, Mérida Martos AM. Prevalencia de hepatitis virales en inmigrantes adultos pakistaníes atendidos en un centro de salud. Med Clin (Barc) 2005; 125: 317.

20. Fuertes C, MARTín LASo MA. El inmigrante en la consulta de atención primaria. An Sist Sanit Navar 2006; 29 (Supl. 1): 9-25.

21. Vázquez Navarrete ML, Terraza Núñez R, Vargas Lorenzo I, Lizana Alcazo T. Necesidades de los profesionales de salud en la atención a la población inmigrante. Gac Sanit 2009; 23: 396-402.

22. Pérez-Arellano JL, Sanz Peláez O. Medicina Interna e infecciones en inmigrantes. Rev Clin Esp 2008; 208: 1-3.

23. Fuertes MC, Elizalde L, de Andrés MR, García Castellano P, Urmeneta S, Uribe JM et al. Atención al paciente inmigrante: realidad y percepción de los profesionales de 6 zonas de Atención Primaria de Navarra. An Sist Sanit Navar 2010; 33: $57-68$.

24. Hernando Arizaleta L, Palomar Rodríguez J, Márquez Cid M, Monteagudo Piqueras O. Impacto de la inmigración sobre la asistencia hospitalaria: frecuentación, casuística y repercusión económica. Gac Sanit 2009; 23: 208-215.

25. López Rillo N, Epelde F. Valoración del uso que hace la población inmigrante de un servicio de urgencias hospitalario. Emergencias 2010; 22: 109-112.

26. Junyent M, MiRó Ò, SÁnchez M. Comparación de la utilización de los servicios de urgencias hospitalarios entre la población inmigrante y la población autóctona. Emergencias 2006; 18: 232-235.

27. MuenNig P, FAHS MC. Health status and hospital utilization of recent immigrants to New York City. Prev Med 2002; 35: 225-231.

28. Picco G. Respuesta a: La inmigración en Canarias y su posible influencia sobre la tuberculosis. Med Clin (Barc) 2001; 117: 517-518. 
29. Castilla J, Urtiaga M, Hueto J, Sola J, Dorronsoro I, Torroba L et al. Evolución en la características epidemiológicas de la tuberculosis en Navarra (19942003). An Sist Sanit Navar 2005; 28: 237-245.

30. Soler Rangel L, García Viejo MA, Jaras Hernández MJ, Vidal Pérez JL, López MesoNero O, Noguerado Asensio A. Análisis de la población atendida en una unidad de tuberculosis en Madrid. Evolución e impacto de la inmigración desde 1997 a 2006. Rev Clin Esp 2009; 209: 467-477.

31. Ramos JM, GutiéRrez F. Tuberculosis e Inmigración. Med Clin (Barc) 2006; 126 : 277-279.

32. Regidor E, Ronda E, Pascual C, Martínez D, Calle ME, Domínguez V. Mortalidad por enfermedades cardiovasculares en inmigrantes residentes en la Comunidad de Madrid. Med Clin (Barc) 2009; 132: 621-624.

33. Solé M, Rodríguez M. Disparidades entre inmigrantes y nativos en el impacto de las condiciones laborales en la salud. Gac Sanit 2010; 24: 145-150. 
